\title{
María Gabriela Cruz Volio. Actos de habla y modulación discursiva en español medieval. Representaciones de (des)cortesía verbal historica. Berlín: Peter Lang. Series: Studia Romanica et Lingüística, 2017, 342 páginas
}

\author{
Paula Albitre
}

Albitre, P. (2021). María Gabriela Cruz Volio. Actos de habla y modulación discursiva en español medieval. Representaciones de (des)cortesía verbal histórica. Berlín: Peter Lang. Series: Studia

Romanica et Lingüística, 2017, 342 páginas. Revista de Filología y Lingüística de la Universidad de Costa Rica, 47(1), e44338. doi: https://doi.org/10.15517/rfl.v47i1.44338

\section{(9) $(1) \Theta \Theta$}

Doi: https://doi.org/10.15517/rfl.v47i1.44338

URL: https://revistas.ucr.ac.cr/index.php/filyling/index 


\section{Reseñas}

\section{María Gabriela Cruz Volio. Actos de habla y modulación discursiva en español medieval. Representaciones de (des)cortesía verbal histórica. Berlín: Peter Lang. Series: Studia Romanica et Lingüística, 2017, 342 páginas}

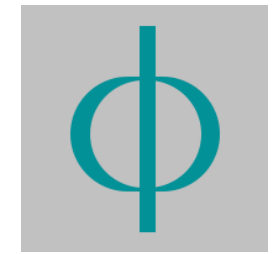

\section{Albitre, Paula}

(iD) Paula Albitre

paulalbitre@gmail.com

Universidad Complutense de Madrid, Instituto

Universitario Menéndez Pidal, Madrid, España

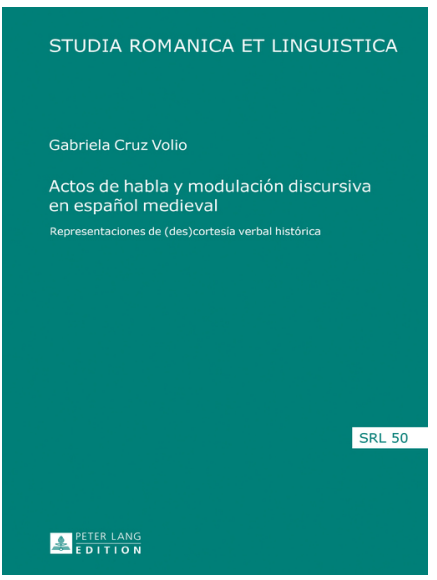

Cruz Volio María Gabriela. Actos de habla y modulación discursiva en español medieval. Representaciones de (des)cortesía verbal histórica. 2017. Berlín. Peter Lang. Series: Studia Romanica et Lingüística. 342 páginaspp.

Revista de Filología y Lingüística de la Universidad

de Costa Rica

Universidad de Costa Rica, Costa Rica

ISSN: 0377-628X

ISSN-e: 2215-2628

Periodicidad: Semestral

vol. 47, núm. 1, 2021

filyling@gmail.com

URL: http://portal.amelica.org/ameli/ jatsRepo/125/1251597029/index.html

DOI: https://doi.org/10.15517/rfl.v47i1.44338 
A pesar de que en el ámbito hispánico la pragmática ha sufrido un notable desarrollo en las últimas décadas, todavía existe una gran carencia de investigaciones que indaguen sobre su manifestación histórica. La obra Actos de habla y modulación discursiva en español medieval. Representaciones de (des)cortesia verbal histórica no solo aporta conocimientos sobre la configuración histórica de la (des)cortesía, sino que también establece una base metodológica para su estudio.

La investigación de la (des)cortesía, desde una perspectiva diacrónica, apenas está comenzada. El reciente interés por esta tipología de estudios se debe, en gran parte, a la mayor disposición de los enfoques posmodernos o discursivos a descubrir el funcionamiento de este fenómeno en estadios anteriores de variedades lingüísticas. Como indica la autora (16), dirigir la mirada a la manifestación histórica de la cortesía sirve también para valorar críticamente la teoría como tal, debido a que esto pone en tela de juicio ciertos presupuestos, como el de la universalidad, al tiempo que ayuda a entender y a profundizar sobre lo que ya se ha investigado en variedades actuales.

A lo largo de este trabajo, fruto de su tesis doctoral, María Gabriela Cruz Volio estudia la representación de la (des)cortesía verbal en español medieval a través de un análisis de la formulación de distintos tipos de actos de habla, expresivos y discursivos, y de la modulación del entorno discursivo. El objetivo principal de esta investigación es proponer un entendimiento de (des)cortesía histórica que tome en cuenta dos factores esenciales: el contexto y los roles interaccionales establecidos en determinadas situaciones discursivas.

Los dos primeros capítulos están destinados a sentar las bases pragmáticas del trabajo y a definir con precisión el objeto de estudio: la (des)cortesía histórica. En el primer capítulo (15-30), la autora expone los objetivos y preguntas de su investigación y realiza un repaso minucioso de los estudios previos elaborados sobre la pragmática y la (des)cortesía histórica en el ámbito romanístico y, más específicamente, en la historia del español.

El segundo capítulo (31-88) explora las fuentes teóricas que sirven de soporte para la investigación, mencionando las principales teorías sobre (des)cortesía verbal, desde los modelos tradicionales (Grice, Brown y Levinson) y posmodernos hasta los acercamientos actuales (Spencer-Oatey, Arndt/Janney, Caffi/Janney). Si bien es cierto que ha habido un gran avance en cuanto a la delimitación teórica y al desarrollo metodológico de la pragmática histórica, no existe todavía un modelo de cortesía global, por lo que Cruz Volio (66) toma en cuenta para la caracterización de la (des)cortesía aportes relevantes de las vertientes tradicional y discursiva, sin adscribirse a un modelo de cortesía preestablecido.

El tercer capítulo (89-102) está dedicado a explicar la metodología del estudio y a presentar el corpus. El enfoque empleado por Cruz Volio (91) se corresponde con un análisis pragmalingüístico y discursivo, en el cual se pretende caracterizar los recursos lingüísticos utilizados para expresar cortesía verbal. De esta forma, se profundiza en el nivel contextual del discurso con el objetivo de explorar los aspectos sociales que determinan usos particulares del lenguaje. Uno de los motivos por las que la autora descarta llevar a cabo una metodología cuantitativa es que muchas funciones pragmáticas no están convencionalizadas en expresiones gramaticales. Es decir, no siempre hay una correspondencia entre forma y función.

La autora parte de una metodología cualitativa para estudiar su corpus, conformado por pasajes dialogados de varias obras de ficción medieval. Desde el punto de vista pragmalingüístico, se realiza una descripción de los recursos léxico-gramaticales empleados en la expresión de actos de habla y su respectiva modulación discursiva. Esto implica que la cortesía, si bien es un fenómeno sociocultural, puede expresarse verbalmente a través de determinados operadores lingüísticos. Por consiguiente, como indica la autora (93), la cortesía atañe tanto al ámbito de la pragmalingüística (su realización lingüística) como al de la sociopragmática (su determinación sociocultural).

Los siguientes tres capítulos incluyen una explicación detallada de la investigación, incluyendo un estudio del nivel del enunciado (capítulo 4), del nivel de la intervención (capítulo 5) y del nivel del intercambio (capítulo 6). 
En el capítulo 4 (103-182) se estudia la codificación lingüística de los actos de habla a través de la revisión de las propiedades de expresión léxico-gramatical para cada clase. Cruz Volio (103) sigue, de manera muy general, la clasificación de Risselada (Risselada, R. (1993). Imperatives and others directive expressions in Latin: a study in the pragmatic of a dead language. Amsterdam: Gieben), pues entiende los actos de habla como categorías difusas en las cuales hay miembros prototípicos y otros situados en la periferia, lo cual dificulta la clasificación de un acto de habla en una clase específica. La autora examina detalladamente la realización lingǘstica de los actos de habla expresivos (saludos y agradecimientos), comisivos (promesas y amenazas), informativos (aserciones y preguntas) y directivos en los pasajes dialógicos de los textos literarios medievales que conforman su corpus. Para la descripción del núcleo del acto de habla directivo, caracterizado por una amplia gama de opciones para su configuración, Cruz Volio (130) distingue los siguientes grupos: formas gramaticales, locuciones y verbos performativos, perífrasis léxicas y, por último, otras formas y estructuras léxico-gramaticales.

En el capítulo 5 (183-258) se realiza el estudio del contexto discursivo de la intervención, pues, como señala Cruz Volio (183), la expresión de la cortesía verbal se extiende más allá de enunciados aislados, motivo por el cual se debe tener en cuenta el entorno lingüístico. La autora sigue las propuestas planteadas por Caffi (Caffi, C. (1999). On mitigation. Journal of Pragmatics, 31(7), 881-909) y Sbisà (Sbisà, M. (2001). Illocutionary force and degrees of strength in language use. Journal of Pragmatics, 33(12), 1791-1814), entendiendo la modulación como un proceso multidimensional que permite incluir aspectos de índole emotiva en lugar de darle prioridad exclusiva a aspectos sociolingüísticos. En función de sus características, la autora señala distintos tipos de modulación en función de qué recursos empleen: derechos y obligaciones, expresiones epistémicas, trabajo relacional, configuración estructural, configuración argumentativa.

En el capítulo 6 (259-278) se revisan las intervenciones reactivas en función de si expresan acuerdo o desacuerdo. Cruz Volio (276) evalúa las distintas formulaciones junto con los movimientos de apoyo que las acompañan y su valor de (des)cortesía. La manifestación de acuerdo se realiza mediante diferentes expresiones, todas ellas corteses, como agradecimientos, la afirmación de coincidencia de deseos o el uso de aserciones o enunciados impersonales en el caso de los rechazos. En el otro lado del continuum se situaría la expresión del desacuerdo, inherentemente descortés. En estos casos, se emplean agresiones verbales que intensifican el rechazo, especialmente cuando existe una notable diferencia de estatus entre los interlocutores.

A modo de síntesis de los resultados, el capítulo 7 (279-316) tiene como objetivo proponer un entendimiento de la (des)cortesía verbal a partir del análisis presentado en los tres capítulos previos. Para ello, la autora se centra primero en explicar la imagen y las expectativas de comportamiento, después hace referencia a los factores situaciones influyentes y, finalmente, especifica el papel que desempeña el tipo textual en la expresión de la (des)cortesía.

A partir de las tendencias observadas en su trabajo, Cruz Volio (317) concluye que la cortesía verbal responde a expectativas de comportamiento relacionadas con el manejo del grado de imposición, retribución, deferencia e involucramiento. Además, corrobora que la representación de la imagen está asociada con los roles sociales e interaccionales que cumplen los personajes según el tipo de texto. Lo cual demuestra que la tipología textual literaria cumple un rol determinante en la expresión de la cortesía y que los textos de ficción son totalmente válidos para evaluar e interpretar la cortesía, pues no solo aportan un marco situacional, sino también un contexto histórico y sociocultural.

Por último, el capítulo 8 (317-321) retoma la perspectiva general del libro al incluir una discusión sobre las implicaciones teóricas y metodológicas derivadas de abordar un tema de pragmática histórica desde fuentes literarias. Las páginas finales del libro incluyen, como anexo (351-358), las tablas de análisis que reflejan la metodología cualitativa realizada sobre las intervenciones aisladas y los pasajes dialógicos del corpus.

Los resultados de esta investigación constatan que la misma noción de (des)cortesía ha ido evolucionando y modificándose históricamente para adaptarse a las actividades sociales de cada momento. En este sentido, Cruz Volio (30) insiste en que las expresiones de cortesía solamente se pueden explicar por determinadas 
condiciones sociales y tipos de comportamiento que cambian a través del tiempo. Aunque presente y pasado estén relacionados, la aplicación directa en estudios históricos de patrones y resultados obtenidos en investigaciones cortesiológicas actuales supone un error. En consecuencia, los estudios históricos deben desarrollar sus propios principios metodológicos, para así atender debidamente a las modificaciones y cambios de cada época.

Este trabajo, gracias a su acertada metodología, supone un punto de partida para futuras investigaciones filológicas. De esta forma se podrá completar la gran laguna textual y cronológica que todavía existe en los estudios sobre pragmática histórica del español y, más especialmente, en los dedicados a la (des)cortesía histórica. Será un trabajo tan largo, costoso y complejo, como provechoso y esencial. 